\title{
HUBUNGAN PENGETAHUAN IBU TENTANG KECERDASAN ANAK GOLDEN PERIOD DENGAN SIKAP IBU DALAM MENSTIMULASI KECERDASAN ANAK GOLDEN PERIOD(Di Posyandu Lingkungan Gondang Legi Kecamatan Sutojayan Kab. Blitar)
}

Siti Komariyah, S.Si.T.M.Kes ${ }^{1}$, Betristasia Puspitasari, S.ST.M.Kes ${ }^{2}$

Akademi Kebidanan Dharma Husada Kediri Jawa Timur

\begin{abstract}
ABSTRAK
Anak merupakan makhluk yang membutuhkan pemeliharaan, pemantauan, kasih sayang dalam tahap pertumbuhan dan perkembangannya. Anak tentu memerlukan nutrisi, stimulasi, pola pengasuhan yang tepat agar masa golden period (0-5 tahun) anak dapat tumbuh dan berkembang secara optimal. Tujuan penelitian mengetahui hubungan antara pengetahuan ibu tentang kecerdasan anak golden period dengan sikap ibu dalam menstimulasi kecerdasan anak golden period.

Desain penelitian yang digunakan adalah korelasi dengan pendekatan cross sectional. Populasinya yaitu ibu yang mempunyai anak balita di posyandu lingkungan Gondang Legi sejumlah 40 responden dengan teknik pengambilan sampel total sampling, sehingga semua sampel diuji menggunakan 2 variabel. Variabel independen yaitu pengetahuan ibu tentang kecerdasan anak golden period, variabel dependen yaitu sikap ibu dalam menstimulasi kecerdasan anak golden period. Pengumpulan data kedua variabel menggunakan kuesioner, selanjutnya dilakukan pengolahan data dengan Editing, Coding, Skoring, Tabulating. Teknik analisa yang digunakan untuk menguji hipotesa adalah Chi Kuadrat dengan $\alpha=0,05$.

Hasil penelitian diperoleh pengetahuan responden tentang kecerdasan anak golden period adalah cukup 26 responden (65\%) dan sikap dalam menstimulasi kecerdasan anak golden period negatif sebanyak 23 responden (57,5\%). Uji statistik Chi Kuadrat didapatkan $t$ hitung lebih besar daripada $t$ tabel (harga 7,45> 5,59) maka H1 diterima.

Dari hasil penelitian dapat disimpulkan ada hubungan pengetahuan ibu tentang kecerdasan anak golden period dengan sikap ibu dalam menstimulasi kecerdasan anak golden period di posyandu Lingkungan Gondang Legi Kecamatan Sutojayan Kabupaten Blitar. Diharapkan kepada pihak tenaga kesehatan lebih meningkatkan penyuluhan tentang kecerdasan anak golden period, dan lebih memberikan perhatian dan pengawasan pada anaknya.
\end{abstract}

Kata Kunci : Pengetahuan, Ibu, Kecerdasan Anak Golden Period, Sikap,Stimulasi 


\section{PENDAHULUAN}

Pembangunan

kesehatan merupakan upaya dari peningkatan kualitas manusia seutuhnya yang harus dilakukan sedini mungkin sejak masa bayi. Salah satu yang harus dilakukan adalah dengan memberikan rangsangan atau stimulasi perkembangan otak sesuai golongan umur anak sedini mungkin.

Anak merupakan makhluk yang membutuhkan pemeliharaan, kasih sayang dan tempat bagi perkembangannya. Anak juga merupakan pribadi yang masih bersih dan peka terhadap rangsanganrangsangan yang berasal dari lingkungan (Ayuningsih, 2012 : 05). Selain itu anak merupakan aset keluarga yang paling besar, dalam tahap pertumbuhan dan perkembangannya. Anak tentu memerlukan nutrisi, stimulasi, pola pengasuhan yang tepat agar masa golden period (0-5 tahun) anak dapat tumbuh dan berkembang secara optimal (Septiari, 2012 : iii).

Kebutuhan stimulasi atau upaya merangsang kecerdasan otak anak untuk memperkenalkan suatu pengetahuan atau ketrampilan baru itu sangat penting dalam peningkatan kecerdasan anak. Stimulasi pada anak dapat dimulai sejak anak dalam kandungan sampai anak berusia balita. Penelitian menunjukkan, mengenalkan pada kegiatan membaca, bahasa, dan matematika sejak usia balita, akan membuat mereka lebih mudah menangkap pelajaran tersebut nantinya (Lalage, 2013 : 46).

Pada usia balita otak anak mengalami pertumbuhan yang sangat pesat. Otak yang cerdas pada dasarnya sangat ditunjang oleh kemampuan seseorang dalam memaksimalkan kerja otak itu sendiri, sehingga otak mampu menyerap berbagai informasi yang diterima untuk disimpan dimemori otak. Saat berusia 1 tahun pertumbuhan otak telah mencapai $70 \%$ dari otak dewasa. Selain itu $70-85 \%$ sel otak yang ada sudah terbentuk secara lengkap. Pada usia 3 tahun otak anak telah mencapai $90 \%$ dari ukuran otak dewasa. Periode ini disebut sebagai periode lompatan pertumbuhan otak. Pada periode ini, sel otak akan sangat peka terhadap lingkungannya dan akan sangat terpengaruh oleh lingkungan positif maupun negatif. Otak yang tumbuh optimal akan memungkinkan pertumbuhan kecerdasan yang optimal pula (Roesli, $2004: 10$ ).

Selain mengalami pertumbuhan kecerdasan pada masa ini balita juga mengalami pertumbuhan fisik dan perkembangan. Pertumbuhan danperkembanganjuga mengalami peningkatan yang sangat pesat. Masa ini sering juga disebut sebagai fase "Golden Period". Golden Period merupakan masa yang sangat penting untuk memperhatikan tumbuh kembang anak secara cermat agar sedini mungkin dapat terdeteksi apabila terjadi kelainan (Nutrisiani, 2010).

Menurut Herbowo Soetomenggolo (2013), macam-macam perkembangan anak tersebut tidak terlepas dari pemberian stimulasi, baik oleh orangtua maupun lingkungannya. Stimulasi yang baik dianggap sebagai kebutuhan otak karena berperan penting pada tingkat kecerdasan otak anak pada masa mendatang.

Pada masa perkembangan inilah, masa bertambahnya kemampuan dan keterampilan balita. Orangtua perlu memperhatikan sejumlah perkembangan motor halus dan motor kasar, serta sosialisasi dan bahasa balita dalam periode keemasan mereka. Gerak-gerak anak, seperti menyusun menara donat adalah salah satu gejala perkembangan motor halusnya (Hanifoza,2012).

Periode emas dapat diwujudkan apabila balita memperoleh stimulasi yang sesuai untuk tumbuh kembang optimal. Dalam hal ini peran ibu sebagai pendidik utama sangatlah diperlukan. Namun, sebagian besar para ibu belum atau tidak memahami hal ini terutama para ibu yang mempunyai tingkat pendidikan dan sosial ekonomi yang relatif rendah. Mereka menganggap bahwa selama anak tidak sakit, berarti anak tidak mengalami masalah kesehatan termasuk pertumbuhan dan 
perkembangannya (Nursalam, 2005 : 31).

Tingkat pengetahuan ibu yang kurang terhadap golden period akan menghambat tumbuh kembang anak dimasa mendatang. Di propinsi banten pada tahun 2010 angka kematian bayi (AKB) mencapai 25,3 per 1000 kelahiran hidup. Dikarenakan para ibu tidak atau kurang memperhatikan tumbuh kembang pada anaknya. Untuk membawa balita ke posyandu setiap bulan saja tidak dilakukan, ibu hamil memeriksakan kehamilannya tidak teratur, tidak memberikan ASI Eksklusif bagi bayi sejak lahir hingga usia enam bulan, tidak memberikan imunisasi lengkap bagi bayi sebelum berumur satu tahun. (Depkes RI, 2010). Selain itu para ibu yang terlalu sibuk dengan karirnya sehingga pada masa emas ini tidak dimanfaatkan dengan sebaik mungkin. Ada juga ibu yang dengan ekonomi rendah pemberian gizi untuk anaknya kurang, sehingga tumbuh kembang anak menjadi terhambat (Septiari, 2012 : 162 ).

Menurut hasil penelitian tentang pengetahuan ibu dalam menstimulasi kecerdasan anak golden period yang dilakukan di Denmark tahun 2012 menunjukkan, populasi sebanyak $50 \mathrm{ibu}$ dan sampel 30 responden. Ibu yang mempunyai tingkat pengetahuan cukup sebanyak 15 responden (50\%). Sedangkan ibu yang memiliki tingkat pengetahuan baik sebanyak 14 responden $(46,7 \%)$ dan hanya 1 responden $(3,3 \%)$ yang memiliki pengetahuan kurang tentang stimulasi. Perlu dilakukan penelitian lebih lanjut mengenai stimulasi perkembangan anak dengan pendekatan lebih mendalam. Khususnya bidan dapat meningkatkan intensitas kegiatan pendidikan kesehatan tentang cara menstimulasi perkembangan anak pada masa golden period (Khairunnisa, 2012).

Di Indonesia terancam tidak memiliki generasi emas dimasa mendatang. Masalah yang tak kunjung teratasi, seperti kekurangan gizi dan nutrisi pada anak-anak adalah menjadi pemicunya. Anak-anak indonesia terancam lemah otak akibat kekurangan gizi. Masalah makanan atau gizi mempengaruhi sekitar 13 persen dari faktor genetik, perilaku dan lingkungan. Menurut Profesor Ali Khomsan pertumbuhan jutaan anak Indonesia terhambat akibat kekurangan gizi kronik saat balita. $36 \%$ balita Indonesia mengalami kekurangan gizi kronik, sedangkan sebanyak 7,8 juta anak Indonesia mengalami keterhambatan pertumbuhan. Satu di antara tiga anak balita memiliki ukuran badan yang lebih pendek dari standar tinggi badan yang diharapkan. Masalah gizi dikatakan juga terkait dengan perkembangan kognitif anak.

Di Jawa Timur sebanyak 38\% kasus gizi buruk, berdasarkan hasil penelitian Tim Penggerak Pendidikan Kesejahteraan Keluarga (PKK) Provinsi Jawa Timur, dikarenakan pola asuh. Kesalahan pola asuh mengakibatkan terjadinya informasi gizi yang salah sehingga anak mengalami kekurangan gizi. Sampai tahun 2011, 20 persen anak balita dari total 2,4 juta anak balita mengalami gizi buruk. Berdasarkan informasi yang dikumpulkan PKK Jatim, anak balita mengalami gizi buruk dikarenakan kesalahan informasi gizi oleh pengasuh atau orang tuanya (Compass, 2012).

Di Kabupaten Blitar status gizi balita $68,3 \%$ balita memiliki status gizi baik, $24,4 \%$ balita memiliki status gizi kurang, dan 7,3\% balita memiliki status gizi buruk (Karyailmiah, 2011).

Pada masa golden period, segala bentuk penyakit, kekurangan gizi, serta kekurangan kasih sayang, akan membawa dampak negatif yang menetap sampai seumur hidupnya. Karena itu, pola pengasuhan yang baik dan benar dibutuhkan untuk menghindarkan risiko tersebut. Upaya pemantauan kesehatan, pertumbuhan dan perkembangan anak serta penanganannya dilakukan di berbagai tingkatan. Salah satunya upaya berbasis masyarakat yang diselenggarakan melalui Posyandu. 
Untuk mengatasi hal ini, orang tua harus dibekali tentang pentingnya nutrisi untuk perkembangan otak anak. Tapi kenyataannya justru orang tua menjadi penyebab anak kekurangan gizi. Di rumah tanggga, terkadang orang tua (ayah) lebih mementingkan membeli rokok ditimbang membeli makanan bergizi untuk anaknya. Selain itu orang tua tidak memahami bahwa pertumbuhan dan perkembangan anak dimulai pada saat anak umur balita (bawah lima tahun).

\section{METODE}

Pada penelitian ini desain penelitian yang digunakan adalah korelasionaldengan pendekatan cross sectional.

Populasi dalam penelitian ini yaitu Ibu yang mempunyai anak balita di Posyandu Lingkungan Gondang Legi Kecamatan Sutojayan Kabupaten Blitar sejumlah 40 orang responSampel dalam penelitian ini adalah semuaibu yang mempunyai anak balita di Posyandu Lingkungan Gondang Legi Kecamatan Sutojayan Kabupaten Blitar sejumlah 40 orang responden .Sampling yang digunakan dalam penelitian ini adalah Total Sampling.

HASIL

Tabel 1: Hubungan Pengetahuan Ibu Tentang Kecerdasan Anak Golden Period Dengan Sikap Ibu Dalam Menstimulasi Kecerdasan Anak Golden PeriodDi Posyandu Lingkungan Gondang Legi Kecamatan Sutojayan Kabupaten Blitar

\begin{tabular}{|c|c|c|c|c|c|c|c|}
\hline \multirow{3}{*}{ No } & \multirow{3}{*}{ Pengetahuan } & \multicolumn{4}{|c|}{ Sikap } & \multirow{2}{*}{\multicolumn{2}{|c|}{ Jumlah }} \\
\hline & & \multicolumn{2}{|c|}{ Positif } & \multicolumn{2}{|c|}{ Negatif } & & \\
\hline & & B & $\%$ & B & $\%$ & B & $\%$ \\
\hline 1 & Baik & 2 & 11,8 & 0 & 0 & 2 & 5 \\
\hline 2 & Cukup & 12 & 70,6 & 14 & 60,9 & 26 & 65 \\
\hline 3 & Kurang & 3 & 17,6 & 9 & 39,1 & 12 & 30 \\
\hline \multicolumn{2}{|r|}{ Jumlah } & 17 & 100 & 23 & 100 & 40 & 100 \\
\hline \multicolumn{4}{|c|}{$\chi^{2}$ hitung $=7,45 \chi^{2}$ tabel $=5,59$} & iitur & $x^{2}+a b$ & $\alpha=$ & \\
\hline
\end{tabular}

\section{DISKUSI}

Berdasarkan hasil penelitian yang telah dilakukan peneliti didapatkan hasil bahwa ada hubungan antara pengetahuan ibu tentang kecerdasan anak golden period dengan sikap ibu dalam menstimulasi kecerdasan anak golden period Di Posyandu Lingkungan Gondang Legi Kecamatan Sutojayan Kabupaten Blitar. Hal ini dapat dilihat dari hasil tabulasi silang, ibu yang berpengetahuan baik dan memiliki sikap positif sebanyak 2 responden $(5 \%)$, tabel (7,45> artinya $\mathrm{H} 0$ ditolak dan $\mathrm{H} 1$ diterima. Maka, ada Hubungan antara Pengetahuan Ibu Tentang Kecerdasan sedangkan ibu yang memiliki pengetahuan baik dengan sikap negatif lebih banyak yaitu sebanyak 0 responden $(0 \%)$. Ibu yang memiliki pengetahuan cukup dengan sikap positif sebanyak 12 responden (30\%) sedangkan ibu yang memiliki pengetahuan cukup dengan sikap negatif sebanyak 14 responden (35\%).

Dari hasil perhitungan uji statistik Chi kuadrat didapatkan $\chi^{2}$ hitung lebih

$$
5,59) \text {. }
$$$$
\text { dari }
$$$$
\text { Ini }
$$

Anak Golden Period dengan Sikap Ibu Dalam Menstimulasi Kecerdasan Anak Golden Period Di Posyandu Lingkungan 
Gondang Legi Kecamatan Sutojayan Kabupaten Blitar.

Pengetahuan merupakan hasil dari tahu, yang terjadi setelah orang melakukan pengindraan terhadap objek tertentu dan pedoman dalam membentuk tindakan seseorang (Maulana, 2009 : 194). Pengetahuan yang cukup tentang kecerdasan anak golden period sangat berpengaruh terhadap sikap ibu dalam menstimulasi kecerdasan anak golden period yang tepat pada anak usia balita.

Dari penjelasan di atas menunjukkan ada hubungan yang negatif antara pengetahuan ibu tentang kecerdasan anak golden period dengan sikap ibu dalam menstimulasi kecerdasan anak golden period.Artinya semakin rendah pengetahuan ibu tentang kecerdasan anak golden period maka semakin rendah pula sikap ibu dalam menstimulasi kecerdasan anak golden period.

Salah satu faktor yang mempengaruhi pengetahuan adalah informasi. Berdasarkan tabel IV.2 dapat diketahui bahwa prosentase tertinggi yang tidak mengetahui informasi tentang kecerdasan anak golden period yaitu sebanyak 34 responden (85\%).

Informasi akan memberikan pengaruh pada pengetahuan seseorang. Meskipun seseorang mempunyai pendidikan yang rendah, tetapi ia mendapat informasi yang baik dari berbagai media seperti televisi, radio, surat kabar atau media cetak lainnya, maka hal itu akan meningkatkan pengetahuan seseorang(Nursalam dan Pariani, 2002: 32).

Pengetahuan berhubungan dengan jumlah informasi yang dimiliki. Dengan pernah mendapatkan informasi dari berbagai sumber informasi antara lain dari sekolah, orang tua, media massa, elektronik, internet dan teman dapat dijadikan dasar oleh para responden untuk mengetahui lebih dalam tentang kecerdasan anak golden period, sehingga menghasilkan tingkat pengetahuan yang baik tentang kecerdasan anak golden period.
Pengetahuan ibu tentang kecerdasan anak golden period sangat penting.Dengan pengetahuan yang baik tentang kecerdasan anak golden period dapat meningkatkan generasi penerus bangsa yang handal.Pengetahuan akan membentuk kepercayaan dan memberikan dasar dalam pengambilan keputusan dan menentukan sikap terhadap objek tertentu.

Dari pengetahuan yang diperoleh ibu dapat mempengaruhi pengambilan sikap dalam menstimulasi kecerdasan anak golden period. Dari tabel IV.2 terdapat 23 responden $(57,5 \%)$ yang memiliki sikap negatif terhadap kecerdasan anak golden period artinya masih memiliki sikap tidak merespon yang tinggi.

Sikap merupakan suatu kecenderungan bertindak dari individu, berupa respon tertutup terhadap stimulus ataupun objek(Maulana, 2009 : 196).Respon tersebut bisa dalam bentuk menerima, mendekati, menyenangi, mengharapkan atau menolak, menjauhi, menghindari, membenci, tidak menyukai obyek tertentu.

Ibu di Posyandu Lingkungan Gondang Legi Kecamatan Sutojayan Kabupaten Blitar lebih memiliki sikap negatif atau tidak menerima tentang stimulasi kecerdasan anak golden period.Sikap atau pandangan mereka tentang stimulasi kecerdasan anak golden period yang meliputi kecerdasan otak, pribadi dan bermasyarakat.Namun masih terdapat sebagian responden yang memiliki sikap positif atau menerima tentang stimulasi kecerdasan anak golden period . Sikap yang positif maupun sikap yang negatif terbentuk dari komponen pengetahuan. Makin banyak segi positif pengetahuan akan makin positif sikap yang terbentuk. Maka makin baik pengetahuan yang dimiliki tentang kecerdasan anak golden period makin tinggi pula sikap tentang kecerdasan anak golden period dan sebaliknya makin buruk pengetahuan yang dimiliki tentang kecerdasan anak golden period makin rendah pula sikap tentang kecerdasan anak golden period. 
Hal ini sesuai dengan pernyataan bahwa dengan meningkatnya pengetahuan akan meningkatkan sikap (Sarwanto, 2010).

Kurangnya sikap ibu tentang kecerdasan anak golden period dipengaruhi salah satunya oleh pengetahuan ibu tentang kecerdasan anak golden period. Keinginan serta motivasi untuk mencari informasiinformasi mengenai kecerdasan anak golden period dan kurang menyerap informasi tentang kecerdasan anak golden period menyebabkan responden memiliki pengetahuan yang kurang. Kurangnya pengetahuan tersebut tentunya juga menyebabkan sikap yang negatif dalam menstimulasi kecerdasan anak golden period.Maka sangat dikhawatirkan hal tersebut dapat meningkatkan rendahnya angka tumbu kembang pada balita.Oleh karena itu, dari pihak responden perlu meningkatkan pengetahuannya tentang kecerdasan anak golden period, dari pihak kesehatan perlu meningkatkan penyuluhan tentang kecerdasan anak golden period dan pemberian perhatian dan pengawasan oleh orang tua kepada anaknya.

Dari hasil penelitian diatas dapat disimpulkan bahwa pengetahuan ibu tentang kecerdasan anak golden period dapat mempengaruhi sikap ibu dalam menstimulasi kecerdasan anak golden period .Dengan demikian menunjukkan bahwa semakin baik pengetahuan ibu tentang kecerdasan anak golden period semakin baik pula sikap ibu dalam menstimulasi kecerdasan anak golden period.
Berdasarkan penelitian yang dilakukan tanggal 10 Juli 2013 dengan jumlah sampel 40 responden maka dapat ditarik kesimpulan penelitian dan dapat diberikan saran bagi pihak yang terkait dengan pengetahuan ibu tentang kecerdasan anak golden period dengan sikap ibu dalam menstimulasi kecerdasan anak golden period.

\section{SIMPULAN}

1. Pengetahuan ibu tentang kecerdasan anak golden period adalah cukup baik yaitu sebanyak 26 responden $(65 \%)$.

2. Sikap ibu dalam menstimulasi kecerdasan anak golden period adalah negatif atau tidak menerima tentang kecerdasan anak golden period yaitu sebanyak 23 responden $(57,5 \%)$.

3. Berdasarkan hasil perhitungan chi kuadrat didapatkan hasil $\chi^{2}$ hitung sebesar 7,45 $\chi^{2}$ tabel 5,59 dapat di simpulkan $\mathrm{H}_{0}$ di tolak $\mathrm{H}_{1}$ dirterima yang artinya menyatakan bahwa ada hubungan antara pengetahuan ibu tentang kecerdasan anak golden period dengan sikap ibu dalam menstimulasi kecerdasan anak golden period. 
DAFTAR PUSTAKA

Departemen Pendidikan Nasional. (2008). Kamus Besar Bahasa Indonesia. Jakarta : PT Gramedia Pustaka Utama

Hidayat, A Aziz Alimul. (2007). Riset Keperawatan dan Teknik Penulisan Ilmiah. Jakarta : Salemba Medika . (2010). Metode Penelitian Kebidanan dan Teknik Analisis Data. Jakarta : Salemba Medika

Lalage, Zerlina. (2013). Menu Pilihan yang Mencerdaskan Otak Bayi \& Balita. Klaten : Abata Press

Niven, Neil. (2002). Psikologi Kesehatan. Jakarta : EGC

Nursalam \& Siti Pariani. (2001). Pendekatan Praktis Metodologi Riset Keperawatan. Jakarta : Infomedika

Nursalam. (2003). Konsep dan Penerapan Metodologi Penelitian Ilmu Keperawatan : Pedoman Skripsi, Tesis dan Instrumen Penelitian Keperawatan. Jakarta : Salemba Medika

(2011). Konsep dan Penerapan Metodologi Penelitian Ilmu Keperawatan. Jakarta : Salemba Medika

(2011). Konsep dan Penerapan Metodologi Penelitian Ilmu Keperawatan : Pedoman Skripsi, Tesis dan Instrumen Penelitian Keperawatan. Jakarta : Salemba Medika

Notoatmojo, Soekidjo. (2010). Metodologi Penelitian Kesehatan. Jakarta : Rineke Cipta
Roesli, Utami. (2005). Mengenal ASI Eksklusif. Yogyakarta : Diva Press

Septiari, Bety Bea. (2012). Mencetak Balita Cerdas dan Pola Asuh Orang Tua. Yogjakarta : Nuha Medika

Suharsimi, Arikunto. (2006). Prosedur Penelitian Suatu Pendekatan Praktek. Edisi Revisi VI. Jakarta : PT. Rineka Cipta

Sunaryo. (2004). Psikologi Untuk Keperawatan. Jakarta : EGC

Wawan, A \& Dewi M. (2010). Teori dan Pengukuran Pengetahuan, Sikap dan Perilaku Manusia. Jogjakarta : Nuha Medika

Anneahira. (2008). Kita tentu sering mendengar tentang periode emas pertumbuhan otak. [Internet]. Available from : $<$ http://www.anneahira.com balitaadalah.htm $>$ [Accessed 12 Mei 2013].

Azzahra, Salma

Salsabila.(2012).Periode emas pertumbuhan otak. [Internet]. Available from : $<$ http://hanifoza.wordpress. com/2012/07/13/periodeemas-pertumbuhan-otakpengalaman-sayamembesarkan-anak/\#more116> [Accessed 12 Mei 2013].

Compas. (2012). Status gizi balita. [Internet]. Available from : $<$ http://www.compas.com> [Accessed 13 Mei 2013].

Khairunnisa. (2012). Perkembangan anak pada masa Golden Period. [Internet]. Available from : $<\underline{\text { http://digilib.unimus.ac.id/ }}$ gdl.php?mod=browse\&op= read\&id=jtptunimus-gdl- 
khairunnis-6793 $>$ Accessed 13 Mei 2013].

Karya Ilmiah. (2011). status gizi balita. [Internet]. Available from : $<$ http://karyailmiah.um.ac.id/index.php/ TIndustri/article/view/1786 9>[Accessed 13 Mei 2013].

Mizan. (2012). Golden Period atau masa keemasan. [Internet]. Available from $<$ http://pelangi.mizan.com/i ndex.php?fuseaction $=$ news det\&id $=237>[$ Accessed 13 Mei 2013].

Maryunami. (2010). Pengetahuan dan sikap ibu dalam tumbuh kembang anak. [Internet]. Available from $<\underline{\text { http://kti-skripsi- }}$ keperawatan.blogspot.com/ 2010/09/gambaranpengetahuan-dan-sikapibu.html $>$ [Accessed 13 Mei 2013].
Okezone. (2008). Tahap awal pertumbuhan anak. [Internet]. Available from : $<$ http://lifestyle.okezone.co $\mathrm{m} / \mathrm{read} / 2008 / 12 / 03 / 196 / 170$ 216/redirect $>$ [Accessed 12 Mei 2013].

PTRC. (2010). Pentingnya pemantauan kesehatan. [Internet]. Available from : $<$ http://www.depkes.go.id/i ndex.php/berita/pressrelease/1597-pentingnyapemantauan-kesehatanpada-masa-periode-emasbalita.html $>$ [Accessed 12 Mei 2013].

Safa. (2011). Buku Balita Cerdas. [Internet]. Availabel from: $<$ http://bukubalitacerdas.blo gspot.com/2011/04/mengint ip-kecerdasan-anak-sejakdini.html $>$ [Accessed 01 Juli 2013]. 